Illinois State University

ISU ReD: Research and eData

Faculty Publications - Psychology

Psychology

2016

\title{
Visuospatial working memory facilitates indoor wayfinding and direction giving
}

\author{
Alycia M. Hund \\ Illinois State University
}

Follow this and additional works at: https://ir.library.illinoisstate.edu/fppsych

\section{Recommended Citation}

Hund, A. M. (2016). Visuospatial working memory facilitates indoor wayfinding and direction giving. Journal of Environmental Psychology, 45, 233-238

This Article is brought to you for free and open access by the Psychology at ISU ReD: Research and eData. It has been accepted for inclusion in Faculty Publications - Psychology by an authorized administrator of ISU ReD: Research and eData. For more information, please contact ISUReD@ilstu.edu. 
Visuospatial Working Memory Facilitates Indoor Wayfinding and Direction Giving

\author{
Alycia M. Hund \\ Illinois State University
}

\begin{abstract}
Acknowledgements
Please address correspondence to Alycia M. Hund, Department of Psychology, Illinois State University, Campus Box 4620, Normal, IL 61790-4620. Telephone: 309-438-7863. Fax: 309-

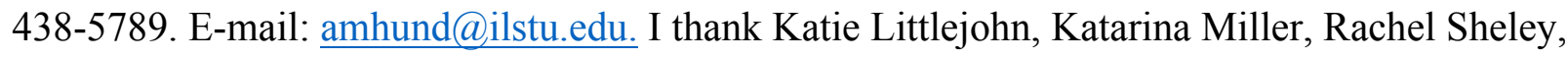
Sarah Sibley, and Amanda Steinbach for help with data collection and coding.
\end{abstract}

Hund, A. M. (2016). Visuospatial working memory facilitates indoor wayfinding and direction giving. Journal of Environmental Psychology, 45, 233-238. 
Visuospatial Working Memory 2

\begin{abstract}
The goal was to test the role of verbal and visuospatial working memory in wayfinding and direction giving in an indoor environment using a dual task paradigm. One hundred ninety-two participants were asked to find their way through one floor of a complex building and to provide directions for a fictitious recipient to find the way in one of three conditions: control (no secondary task), verbal dual task (word-nonword judgments as secondary task), or visuospatial dual task (clock hand judgments as secondary task). Wayfinding was slower in the visuospatial dual task condition than in the control condition, with the verbal condition intermediate. Directions were less accurate in the visuospatial dual task condition than in control and verbal conditions. Women provided more information in wayfinding directions than did men. Together, these findings indicate that visuospatial working memory plays an important role in wayfinding and direction giving in an indoor environment.
\end{abstract}

Keywords: working memory, wayfinding, direction giving, visuospatial, verbal 
Visuospatial Working Memory Facilitates Indoor Wayfinding and Direction Giving Finding our way from place to place is an essential part of everyday life. Giving directions to others to facilitate wayfinding also is important, especially when finding unfamiliar locations (Allen, 1999). Wayfinding directions remain commonplace-even in the age of digital maps and global positioning devices filled with spatial details - though directions vary with regard to the types and specificity of features included and their overall effectiveness (Daniel, Tom, Manghi, \& Denis, 2003; Devlin, 2003; Lovelace, Hegarty, \& Montello, 1999; Padgitt \& Hund, 2012). Direction giving has been studied in a variety of contexts, including college campuses, gas stations, and shopping areas, and in a variety of cities around the world (Denis, Pazzaglia, Cornoldi, \& Bertolo, 1999; Ewald, 2010; Golding, Graesser, \& Hauselt, 1996; Hölscher et al., 2011; Mark \& Gould, 1995).

From a basic research perspective, it is important to understand the cognitive processes that support successful wayfinding and direction giving. From an applied perspective, these findings are essential for helping people find their way efficiently, especially when timing is critical, such as finding the locations of events for which we must be on time and wayfinding in emergency situations. Previous research has demonstrated that verbal and visuospatial aspects of working memory are important for wayfinding (Garden, Cornoldi, \& Logie, 2002; Meilinger, Knauff, \& Bulthoff, 2008). The purpose of this study was to confirm the effects of verbal and visuospatial working memory on indoor wayfinding and to test their effects on direction giving using a dual task paradigm. This work extends previous research using dual tasks to direction giving, as well as to an indoor environment, providing valuable details about the importance of working memory in a variety of contexts. 
According to Baddeley (2003), working memory can be conceptualized as a three-part system that includes the central executive and two storage systems: the phonological loop and the visuospatial sketchpad. The phonological loop stores verbal cues, such as words and numbers, temporarily (Baddeley, 2003). In wayfinding, street names and building descriptors would utilize the phonological loop. Moreover, the sequence of steps needed for successful wayfinding could be coded verbally, using the phonological loop. Similarly, direction giving would place high demands on the phonological loop given the verbal nature of the task. In contrast, the visuospatial sketchpad stores visual and spatial cues, such as maps, images, and cardinal directions and spatial patterns (Baddeley, 2003). These details are important for creating and maintaining integrated representations of space and therefore may provide a foundation for skillful wayfinding and direction giving. ${ }^{1}$ The central executive coordinates attentional resources and processing by both storage systems (Baddeley, 2003). Executive resources are important for coordinating task demands needed to interact with other people and the environment during wayfinding and direction giving. Given that wayfinding and direction giving are demanding cognitive tasks that require integration of multiple details across time and space, as well as communicators and goals (e.g., Couclelis, 1996; Golledge, 1999), we would expect that working memory would be important for successful functioning in both domains. It is important to note that wayfinding and direction giving are separate processes. Both are included in this study to provide details about the role of working memory in a variety of spatially demanding contexts. In fact, the purpose is to extend the literature demonstrating the role of working memory in wayfinding to another arena, that is, direction giving, as well as to utilize an indoor environment. One common approach for testing the effects of working memory components is via a dual task paradigm in which participants are asked to complete a primary task, such as learning 
and traversing routes through an environment, along with a secondary task that places demands on one or more working memory system, such as repeating sequences of digits. If performance on the primary task is less efficient (i.e., slower and/or less accurate) while completing a secondary task relative to completing only the primary task, then researchers conclude that the aspect of working memory taxed by the secondary task is important for completing the primary task. For example, Hermer-Vasquez, Spelke, and Katsnelson (1999) found that verbal shadowing impaired older children and adults' ability to reorient following disorientation in order to search for a hidden object, suggesting that verbal working memory is important. In fact, we know that both verbal and visuospatial details are used to support wayfinding. Wen, Ishikawa, and Sato (2011) found that people with a good sense of direction encoded routes verbally and spatially and integrated details into survey representations. In contrast, people with a poor sense of direction used verbal and visual details only and relied on route knowledge. These findings confirm the importance of working memory for effective acquisition of spatial knowledge.

Garden et al. (2002) used a dual task approach to test the role of working memory in route learning. In the first study, participants learned sequenced routes from a map and then were asked to recognize them under dual task demands. One secondary task was a concurrent articulatory suppression task, which taxed the phonological loop. The other was a spatial tapping task, which taxed the visuospatial sketchpad. Performing either a concurrent spatial or verbal task diminished route learning performance. Route recognition was disrupted by spatial tapping (more than articulatory suppression), confirming the role of visuospatial working memory in route recognition. The second study involved wayfinding through Padova, Italy, during which the same dual tasks were utilized. Participants performed the secondary tasks while following the researcher through the city center to learn the route and also when attempting to recreate the 
route during test. Two routes were used, and their order and the secondary task performed were counterbalanced. Performance was compared to a control group who did not complete the secondary tasks. As expected, performance was worse for participants who completed secondary tasks relative to participants in the control group who focused only on the primary task. Interestingly, participants with high spatial ability were more affected by the spatial tapping task, and participants with low spatial ability were more affected by the articulatory suppression task. Overall, Garden et al. concluded that verbal and visuospatial aspects of working memory are involved in learning, recognizing, and recreating routes. Nonetheless, additional research is needed to understand the role of working memory in supporting complex wayfinding processes in a variety of everyday environments, including indoors.

Meilinger et al. (2008) extended this line of research by including verbal and visual secondary tasks during learning about a virtual city in preparation for wayfinding. Participants learned a route by watching a video. During learning, participants completing the verbal dual task were asked to listen to auditory stimuli and make word or non-word judgments, whereas participants completing the visuospatial dual task were asked to listen to times of day and judge whether the analog clock hands depicting the time would be in the same or different halves of the clock. Participants in the control condition learned the virtual route without a dual task. After the learning phase, participants were asked to navigate through the virtual city using the route information they had learned from the video. No dual task was included during wayfinding for participants in any condition. As expected, wayfinding performance declined in the dual task conditions relative to the control condition, suggesting that verbal and visuospatial working memory were being utilized to learn routes through the virtual city. Because this study used dual tasks during learning only and was conducted using a virtual city, these findings leave 
unanswered questions about the role of working memory during wayfinding itself, as well as extensions to other types of environments, including indoor environments.

A recent study by Hölscher et al. (2011) sought to understand the processes involved in route planning for wayfinding and direction giving. Participants were asked to wayfind through downtown Freiburg, Germany and to give directions to someone else to facilitate wayfinding. The first experiment compared route descriptions and wayfinding when participants were asked to select the shortest route. Route descriptions during planning included fewer turns and streets to utilize main thoroughfares, whereas actual wayfinding routes contained more turns and minor streets, making them shorter overall. A control study demonstrated that these changes were not simply due to a second opportunity to plan the route, suggesting that the perceptual details available during wayfinding facilitated updated route planning while traversing the way. The second experiment utilized three starting locations and destinations in downtown Freiburg. Participants were asked to plan a route for themselves, to plan a route for someone unfamiliar with the area, and to find their way (in counterbalanced order). Again, routes were shorter but had more streets and turns when navigating than when planning routes, especially routes for others. Routes for self were intermediate. Responses to open ended questions and analysis of think aloud protocols provided further evidence that wayfinding involves online processing, that is, continuous monitoring of plans relative to environmental and task demands. Overall, these findings highlight the importance of visual details in the environment for wayfinding and the importance of memory and visual cues when describing the best route to someone else. Importantly, these findings leave unanswered questions about the role of working memory during the direction giving process, as well as extensions to other types of environments, including indoor environments. 
The goal of this study was to confirm the role of verbal and visuospatial working memory in wayfinding and to test their role in direction giving in an indoor environment using a dual task paradigm. Participants were asked to find their way through one floor of a complex building and to provide directions for a fictitious recipient to find the way in one of three conditions: control (no secondary task), verbal dual task (word-nonword judgments as secondary task), or visuospatial dual task (clock hand judgments as secondary task). Based on previous findings documenting clear involvement of verbal and visuospatial working memory in wayfinding in cities (Garden et al., 2002; Meilinger et al., 2008), it was expected that indoor wayfinding would be slower in the verbal and visuospatial dual task conditions than in the control condition. Further, it was expected that performance in the verbal dual task condition might be intermediate, suggesting a stronger role of visuospatial working memory. Although previous research has not used dual task paradigms to assess the role of visuospatial and verbal working memory during direction giving, it was expected that wayfinding directions would be less detailed and less accurate in the verbal and visuospatial dual task conditions than in control condition, given the importance of both aspects of working memory for the spatial and verbal processing needed to provide wayfinding directions (Vanetti \& Allen, 1988; see also Taylor \& Tversky, 1996). Although analysis of gender differences was not the main goal of the present study, such analyses were included given the prominence of gender differences in wayfinding and direction giving (Allen, 2000; Cherney, Brabec, \& Runco, 2008; Devlin, 2003; Ewald, 2010; Lawton, 1996, 2001, 2010; Pazzaglia \& De Beni, 2001; Saucier et al., 2002; Ward, Newcombe, \& Overton, 1986).

\section{Method}

\section{Participants}


Participants were 192 undergraduate students (99 women, 93 men) at a large public university recruited from the psychology participant pool. All participants were 18 years or older ( $M=20$ years 1 month, $S D=3$ years 0 months).

\section{Materials}

\section{Verbal Secondary Task Word List}

A list of 96 English words and non-words was used to tax verbal working memory. The real words included two syllables and were selected from a list of the 10,000 most commonly used words in television and film in 2006 in an attempt to use words that would be heard frequently, and thus were very familiar. Non-words were created by changing the vowel sound in the first syllable of each word (e.g., katchen instead of kitchen). The same random ordering was used for all participants.

\section{Visual Secondary Task Time List}

A list of 100 randomly selected times of day was used to tax visuospatial working memory. Each time was selected from all possible times in five-minute increments (e.g., 2:05) with the constraint that neither the hour nor the minute hand of the clock could be on the 3 or the 9 on the clock, given these were on the boundary between the two halves of the clock (i.e., no 3 or 9 o'clock times or 15 or 45 minute times were included).

\section{Design and Procedure}

This project was approved by the university's Institutional Review Board. Participants granted written informed consent before beginning the study. They were tested individually. The indoor environment included the public hallways of the basement of a complex university building. Participants were allowed to walk around the environment for three minutes to familiarize themselves with their surroundings prior to the first trial. The starting locations for 
each of the trials included a seminar classroom, a research suite, and a small classroom. Ending locations included the computer classroom, the elevators, and the vending machines, respectively. The most efficient routes included 4 turns each and traversed several sections of the basement. Responses on the post-study questionnaire indicated that participants were not very familiar with the basement environment overall $(M=1.86, S D=.92$, average rating for two questions using a 7-point scale where higher scores indicated greater familiarity). On each trial, participants were taken to a starting location and told the destination. Then, they were asked to find their way, to write directions for someone familiar with the basement, or to write directions for someone unfamiliar with the basement. Participants remained at the starting location while writing directions. The inclusion of multiple direction giving trials was inspired by the work of Hölscher et al. (2011), as well as the many studies demonstrating that recipient characteristics influence direction-giving (e.g., Hölscher et al., 2011; Hund, Schmettow, \& Noordzij, 2012; Newman-Norlund et al., 2009). The order of wayfinding and direction giving trials was counterbalanced across participants. Researchers timed wayfinding progress using a stopwatch, beginning when the researcher said go and ending when the participant said stop to indicate reaching the destination. Wayfinding directions were coded based on accuracy and information provided (Hund \& Padgitt, 2010). Accurate directions contained enough details to allow someone to get from the starting location to the destination and did not include incorrect details such as wrong turns. Incorrect directions contained insufficient or incorrect details. Information provided was coded with regard to cardinal directions (e.g., north, south, east, west), distance (e.g., feet/meters or steps), left/right, landmarks (e.g., disambiguating features of the environment, such as the drinking fountain, benches, or bulletin boards), or other (e.g., disambiguating features of the environment not accounted for in other categories, such as " $\mathrm{T}$ " 
intersections in hallways), and the total number of details was calculated. To establish inter-rater reliability, two independent raters coded direction accuracy and information for 36 participants ( $18.75 \%$ of the sample). Intraclass correlation coefficients were .75 for accuracy and .98 for information provided.

Participants were randomly assigned to one of three dual task conditions: control, verbal dual task, or visuospatial dual task (adapted from Meilinger et al., 2008). Participants in the verbal group were asked to decide whether each item they heard was a real English word or not while finding their way or providing wayfinding directions. Participants in the visuospatial group were asked to decide whether each time they heard would involve clock hands on the "same" half or "different" halves if the clock were divided horizontally at 3 and 9 while finding their way or providing wayfinding directions. For example, if the time were 1:05, the correct answer would be same, given both the hour and minute hands would be in the top half of the clock. In contrast, if the time were $2: 25$, the correct answer would be different, given the hour hand would be in the top half and the minute hand would be in the bottom half of the clock. Participants in the control condition did not complete a secondary task during wayfinding or direction giving.

\section{Results}

The goal of this study was to test the influence of verbal and visuospatial working memory on wayfinding and direction giving in an indoor environment. It was expected that performance would decline when working memory demands increased, with effects most dramatic for visuospatial working memory. Gender differences were tested, given their prominence in wayfinding and direction giving (e.g., Lawton, 2010), and recipient familiarity with the environment was analyzed to test the influence of recipient characteristics (e.g., Hölscher et al., 2011; Hund et al., 2012). The accuracy of wayfinding directions was analyzed 
using a Dual Task Condition (control, verbal dual task, visuospatial dual task) x Gender (women, men) x Recipient Familiarity (unfamiliar with the environment, familiar with the environment) mixed model Analysis of Variance (ANOVA). As expected, this analysis yielded a significant main effect of dual task condition, $F(2,186)=3.61, p<.05, \eta_{\mathrm{p}}^{2}=.04$. Fisher's LSD follow up tests indicated that participants in the visuospatial condition provided wayfinding directions that were significantly less accurate $(M=.13, S E=.04)$ than did participants in the control $(M=.27$, $S E=.04)$ and verbal conditions $(M=.27, S E=.04)$. Performance for the latter two conditions did not differ (see Figure 1). Analysis of the overall number of details provided in wayfinding directions revealed no effects of dual task condition, suggesting little influence of working memory on the number of details provided in this paradigm. Overall, women provided significantly more details in their wayfinding directions $(M=5.50, S E=.17)$ than did men $(M=$ 4.96, $S E=.18), F(1,186)=4.83, p<.05, \eta_{\mathrm{p}}^{2}=.03($ see Figure 2$)$.

Wayfinding times were analyzed using a Dual Task Condition x Gender ANOVA. Although the overall analysis yielded no significant effects, planned comparisons of the three dual task conditions indicated that wayfinding was significantly slower in the visuospatial dual task condition $(M=59.10 \mathrm{~s}, S E=2.80)$ than in the control condition $(M=50.38 \mathrm{~s}, S E=2.63)$. The verbal dual task condition was intermediate and did not differ from the other conditions ( $M$ $=55.46 \mathrm{~s}, S E=2.71$; see Figure 3).

\section{Discussion}

The goal was to confirm the influence of visuospatial and verbal working memory on wayfinding and to test their effect on direction giving in an indoor environment. As expected, wayfinding directions were less accurate when participants were completing a concurrent task that taxed their visuospatial working memory (e.g., making judgments about analog clock hands 
for given times), suggesting that visuospatial working memory is important for generating accurate wayfinding directions. This demonstration that visuospatial working memory processes are involved in direction giving is an important addition to the literature, as previous studies had not probed working memory and direction giving using dual task paradigms. The present findings are consistent with results from Hölscher et al. (2011), which found that visual details were implicated in route planning and giving good directions. They also are consistent with findings indicating that spatial abilities are important for direction giving and following (Vanetti \& Allen, 1988). As such, this growing body of literature suggests that people access visual and/or spatial details when called upon to provide wayfinding directions, perhaps focusing on visualizing the environment, including the starting location and destination and a suitable route to traverse from one to the other. The number of details provided in wayfinding directions did not differ as a function of working memory load; however, women provided more details than did men. This gender difference is consistent with numerous findings demonstrating more proficient verbal abilities among women (Maccoby \& Jacklin, 1974, but see Hyde \& Linn, 1988). These findings also seem consistent with many studies showing gender differences in direction giving for wayfinding (e.g., Devlin, 2003; Ewald, 2010; Hund, 2014; Lawton, 2001; Ward et al., 1986).

It is interesting to note that wayfinding directions were not very accurate overall, though it is common for directions to be ambiguous, yet still perceived as clear and helpful, given wayfinders have access to environmental cues during wayfinding that can help resolve ambiguity (Riesbeck, 1980). It is important to note that the verbal secondary task used here did not adversely affect direction giving, despite the verbal processing necessary to generate directions. It is possible that subtle differences exist but were not evident here given the research design 
utilized. For example, perhaps fine-grained coding of the timing of providing directions would indicate more pauses or longer duration overall when under verbal load. It is also possible that a more challenging verbal secondary task is needed to detect differences. Finally, the present findings did not indicate differences in wayfinding directions based on recipient familiarity with the basement environment. These findings are inconsistent with the body of research demonstrating clear differences in directions as a function of recipient characteristics (Hölscher et al., 2011; Hund et al., 2012; Newman-Norlund et al., 2009). It is possible that the increased working memory load disrupted the cognitively demanding processes required to hold in mind details about recipient preferences or characteristics. This conjecture deserves further investigation in future research.

As expected, wayfinding was significantly slower when participants were busy with a concurrent visuospatial task condition than when they were wayfinding only. Wayfinding time was intermediate when participants were busy with a concurrent verbal task. These results are only partially consistent with previous dual task studies of wayfinding in that visuospatial working memory was implicated (Garden et al., 2002; Meilinger et al., 2008); however, in the present study, verbal working memory was not implicated as it had been in the previous studies involving wayfinding through cities. In some ways, the present results are similar to the findings of Garden et al. (2002), which revealed a greater emphasis of the visuospatial sketchpad during wayfinding for participants with high spatial ability. Moreover, Nori, Gandicelli, and Giusberti (2009) found that performance on four visuo-spatial working memory tasks (mental rotation, Corsi blocks, copying, and spatial problem) was related to wayfinding through an unfamiliar botanical garden. In particular, participants with high visuospatial working memory made fewer errors, paused less often, and finished wayfinding more quickly than did participants with low 
visuospatial working memory. Similarly, Fenner, Heathcote, and Jerrams-Smith (2000) found that children with higher visuo-spatial ability made fewer wayfinding errors while traversing a college campus than did children with lower visuo-spatial ability. There were no differences in wayfinding errors based on verbal ability. These measures of ability were broader than working memory; however, assessment included a Corsi blocks measure of visuospatial working memory and a digit span measure of verbal working memory. Overall, the present findings suggest that visuospatial working memory may be more important for indoor wayfinding than is verbal working memory, but the extent to which both processes (and overlapping processes such as executive control) operate remains unclear. Clearly, additional research is needed, particularly using dual-task paradigms, to determine the effect of working memory components on wayfinding in a variety of contexts, including complex indoor environments.

In conclusion, this research is key to understanding the processes involved in wayfinding and direction giving processes. The present findings point to a strong role of visuospatial working memory in supporting fast wayfinding and accurate direction giving. These findings suggest that efforts to support wayfinding should take into account working memory demands, perhaps by limiting the number of details participants must hold in mind while traversing an environment. We know that directions with too many (i.e., over-determinant) details tax working memory and therefore are not preferred for wayfinding (Schneider \& Taylor, 1999). Including verbal descriptions and visuospatial details such as maps and route markers during wayfinding would be beneficial, as would providing opportunities to seek assistance from employees or kiosks (Hund \& Gill, 2014; Streeter et al., 1985). Future research should continue to clarify the mechanisms by which visuospatial and/or verbal working memory facilitate skillful wayfinding and direction giving by assessing individual differences, including dyadic analysis, and 
extending to more complex environments while refining measurement of working memory and performance overall. In addition, future studies should examine how environmental familiarity and wayfinding strategies or preferences interact with working memory to support skillful wayfinding and direction giving. Together, these findings would add valuable details not only regarding how people find their way from place to place, but also how they give directions to help others do so. 


\section{References}

Allen, G. L. (1999). Spatial abilities, cognitive maps, and wayfinding: Bases for individual differences in spatial cognition and behavior. In R. G. Golledge (Ed.), Wayfinding behavior: Cognitive mapping and other spatial processes (pp. 46-80). Baltimore, MD: Johns Hopkins University Press.

Allen, G. L. (2000). Principles and practices for communicating route knowledge. Applied Cognitive Psychology, 14, 333-359.

Baddeley, A. (2003). Working memory: Looking back and looking forward. Nature Reviews Neuroscience, 4(10), 829-839.

Cherney, I. D., Brabec, C. M., \& Runco, D. V. (2008). Mapping out spatial ability: Sex differences in way-finding ability. Perceptual and Motor Skills, 107, 747-760.

Couclelis, H. (1996). Verbal directions for way-finding: Space, cognition, and language. GeoJournal Library: The Construction of Cognitive Maps, 32, 133-153.

Daniel, M-P., Tom, A., Manghi, E., \& Denis, M. (2003). Testing the value of route directions through navigational performance. Spatial Cognition and Computation, 3, 269-289.

Denis, M., Pazzaglia, F., Cornoldi, C., \& Bertolo, L. (1999). Spatial discourse and navigation: An analysis of route directions in the city of Venice. Applied Cognitive Psychology, 13, 145-174.

Devlin, A. S. (2003). Giving directions: Gender and perceived quality. Journal of Applied Social Psychology, 33, 1530-1551.

Ewald, J. D. (2010). Do you know where X is? Direction-giving and male/female directiongivers. Journal of Pragmatics, 42, 2549-2561. 
Fenner, J., Heathcote, D., \& Jerrams-Smith, J. (2000). The development of wayfinding competency: Asymmetrical effects of visuo-spatial and verbal ability. Journal of Environmental Psychology, 20, 165-175.

Garden, S., Cornoldi, C., \& Logie, R. H. (2002). Visuo-spatial working memory in navigation. Applied Cognitive Psychology, 16, 35-50.

Golding, J. M., Graesser A. C., \& Hauselt, J. (1996). The process of answering direction-giving questions when someone is lost on a university campus: The role of pragmatics. Applied Cognitive Psychology, 10, 23-39.

Golledge, R. G. (1999). Human wayfinding and cognitive maps. In R. G. Golledge (Ed.), Wayfinding behavior: Cognitive mapping and other spatial processes (pp. 5-45). Baltimore, MD: Johns Hopkins University Press.

Hermer-Vasquez, L., Spelke, E. S., \& Katsnelson, A. S. (1999). Sources of flexibility in human cognition: Dual-task studies of space and language. Cognitive Psychology, 39, 3-36.

Hölscher, C., Tenbrink, T., \& Wiener, J. M. (2011). Would you follow your own route description? Cognitive strategies in urban route planning. Cognition, 121, 228-247.

Hund, A. M. (2014). Using spatial strategies to facilitate skillful wayfinding and spatial problem solving: Implications for education. In D. R. Montello, K. Grossner, K., \& D. G. Janelle (Eds.), Space in mind: Concepts for spatial learning and education (pp. 195-216). Cambridge, MA: MIT Press.

Hund, A. M., \& Gill, D. M. (2014). What constitutes effective wayfinding directions: The role of descriptive cues and memory demands. Journal of Environmental Psychology, 38, 217234. 
Hund, A. M., \& Padgitt, A. J. (2010). Direction giving and following in the service of wayfinding in a complex indoor environment. Journal of Environmental Psychology, 30, $553-564$

Hund, A. M., Schmettow, M., \& Noordzij, M. L. (2012). The impact of culture and recipient perspective on direction giving in the service of wayfinding. Journal of Environmental Psychology, 32, 327-336.

Hyde, J. S., \& Linn, M. C. (1988). Gender differences in verbal ability: A meta-analysis. Psychological Bulletin, 104, 53-69.

Lawton, C. A. (1996). Strategies for indoor wayfinding: The role of orientation. Journal of Environmental Psychology, 16, 137-145.

Lawton, C. A. (2001). Gender and regional differences in spatial referents used in direction giving. Sex Roles, 44, 321-336.

Lawton, C. A. (2010). Gender, spatial abilities, and wayfinding. In J. C. Chrisler \&D. R. McCreary (Eds.), Handbook of gender research in psychology (pp. 317-341). New York, NY: Springer.

Lovelace, K. L., Hegarty, M., \& Montello, D. R. (1999). Elements of good route directions in familiar and unfamiliar environments. In C. Freksa \& D. M. Mark (Eds.), Spatial Information Theory: Cognition and Computational Foundations of Geographic Information Science (pp. 65-82). Berlin, Germany: Springer.

Maccoby, E. E., \& Jacklin, C. N. (1974). The Psychology of Sex Differences. Chicago, IL: The University of Chicago Press.

Mark, D. M., \& Gould, M. D. (1995). Wayfinding directions as discourse: Verbal directions in English and Spanish. In J. F. Duchan, G. A. Bruder, \& L. E. Hewitt (Eds.) Deixis in 
narrative: A cognitive science perspective (pp. 387-405). Hillsdale, NJ: Lawrence Erlbaum.

Meilinger, T., Knauff, M., \& Bulthoff, H. H. (2008). Working memory in wayfinding: A dual task experiment in a virtual city. Cognitive Science, 32, 755-770.

Newman-Norlund, S. E., Noordzij, M. L., Newman-Norlund, R. D., Volman, I. A. C., de Ruiter, J. P., Hagoort, P., et al. (2009). Recipient design in tacit communication. Cognition, 111, $46-54$.

Nori, R., Gandicelli, S., \& Giusberti, F. (2009). Individual differences in visuo-spatial working memory and real-world wayfinding. Swiss Journal of Psychology, 68, 7-16.

Pazzaglia, F., \& De Beni, R. (2001). Strategies of processing spatial information in survey and landmark-centered individuals. European Journal of Cognitive Psychology, 13, 493-508.

Riesbeck, C. K. (1980). You can't miss it: Judging the clarity of directions. Cognitive Science, 4, 285-303.

Saucier, D. M., Green, S. M., Leason, J., MacFadden, A., Bell, S., \& Elias, L. J. (2002). Are sex differences in navigation caused by sexually dimorphic strategies or by differences in the ability to use the strategies? Behavioral Neuroscience, 116, 403-410.

Schneider, L. F., \& Taylor, H. A. (1999). How do you get there from here? Mental representations of route descriptions. Applied Cognitive Psychology, 13, 415-441.

Streeter, L.A., Vitello, D., and Wonsiewicz, S.A. (1985). How to tell people where to go: Comparing navigational aids. International Journal of Man-Machine Studies, 22, 549562.

Taylor, H. A., \& Tversky, B. (1996). Perspective in spatial descriptions. Journal of Memory and Language, 35, 371-391. 
Vanetti, E. J., \& Allen, G. L. (1988). Communicating environmental knowledge: The impact of verbal and spatial abilities on the production and comprehension of route directions. Environment and Behavior, 20, 667-682.

Ward, S. L., Newcombe, N., \& Overton, W. F. (1986). Turn left at the church, or three miles north: A study of direction giving and sex differences. Environment and Behavior, 18, 192-213.

Wen, W., Ishikawa, T., \& Sato, T. (2011). Working memory in spatial knowledge acquisition: Differences in encoding processes and sense of direction. Applied Cognitive Psychology, $25,654-662$.

Woodin, M. E., \& Allport, A. (1998). Independent reference frames in human spatial memory: Body-centered and environment-centered coding in near and far space. Memory \& Cognition, 26, 1109-1116. 
Visuospatial Working Memory 22

\section{Footnote}

${ }^{1}$ Spatial cognition researchers often make distinctions between egocentric and allocentric coding (or route and survey strategies/perspectives; Lawton, 1996; Taylor \& Tversky, 1996; Woodin \& Allport, 1998). These distinctions are not considered in Baddeley's model of working memory and are beyond the scope of the present project. It is important to note that wayfinding and direction giving can rely on both route and survey perspectives (Hund, 2014; Hund \& Gill, 2014; Hund \& Padgitt, 2010). 
Visuospatial Working Memory 23

\section{Figure Captions}

Figure 1: Overall accuracy of directions provided for wayfinding by female and male participants in each dual task condition.

Figure 2: Total number of details provided in directions for wayfinding by female and male participants in each dual task condition.

Figure 3: Wayfinding time for female and male participants in each dual task condition. 
Visuospatial Working Memory 24

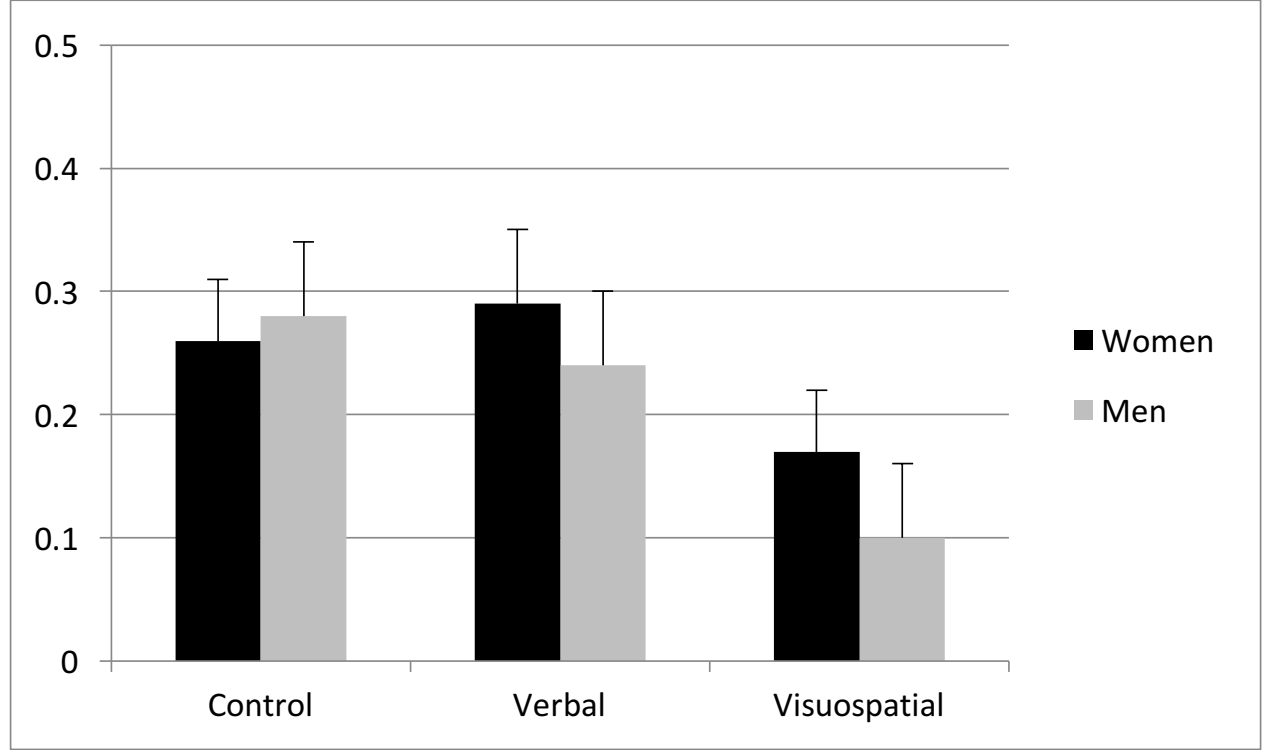


Visuospatial Working Memory 25

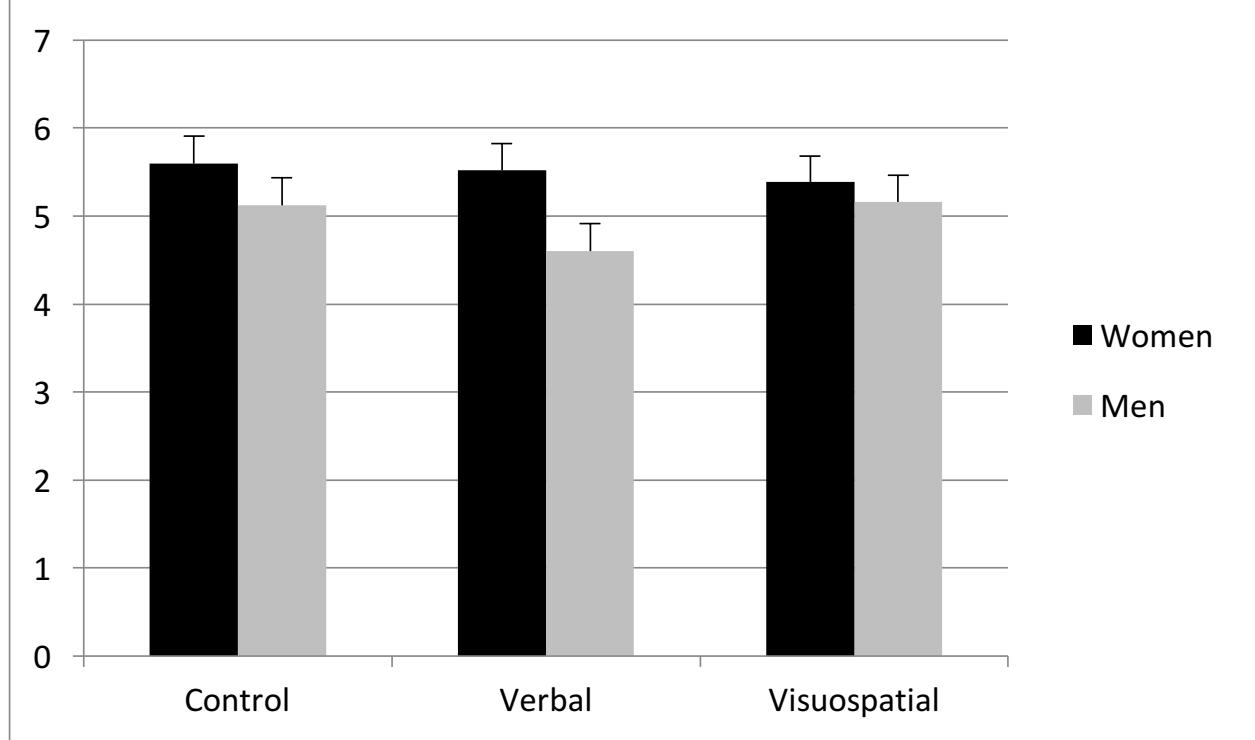


Visuospatial Working Memory 26

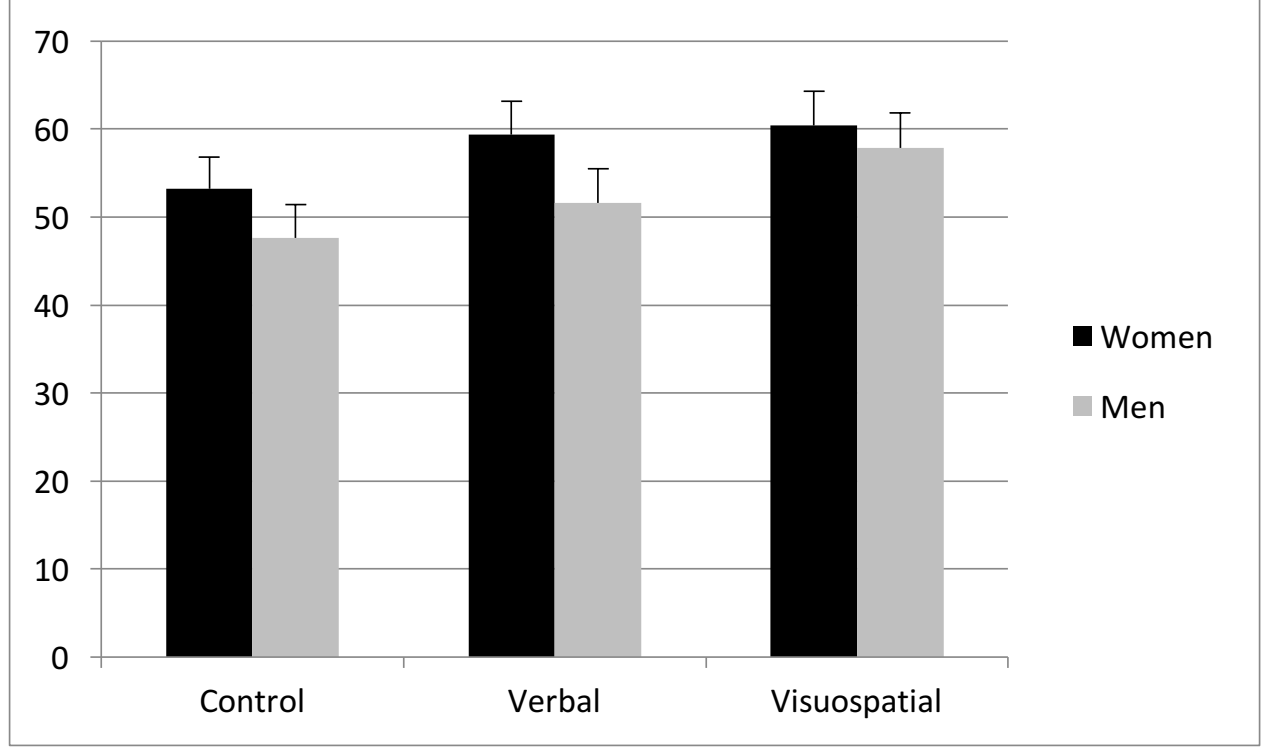

